\title{
Winter mixed layer depth and spring bloom along the Kuroshio front: implications for the Japanese sardine stock
}

\author{
Haruka Nishikawa ${ }^{1,4, *}$, Ichiro Yasuda ${ }^{1}$, Kosei Komatsu ${ }^{1}$, Hideharu Sasaki ${ }^{2}$, \\ Yoshikazu Sasai ${ }^{2}$, Takashi Setou ${ }^{3}$, Manabu Shimizu ${ }^{3}$ \\ ${ }^{1}$ Atmosphere and Ocean Research Institute, The University of Tokyo, 5-1-5, Kashiwanoha, Kashiwa-shi, Chiba 277-8568, Japan \\ ${ }^{2}$ Japan Agency for Marine-Earth Science and Technology, 3173-25, Showa-machi, Kanazawa-ku, Yokohama 236-0001, Japan \\ ${ }^{3}$ National Research Institute of Fisheries Science, Fisheries Research Agency, 2-12-4, Fukuura, Kanazawa-ku, \\ Yokohama 236-8648, Japan \\ ${ }^{4}$ Present address: Japan Agency for Marine-Earth Science and Technology, 3173-25, Showa-machi, Kanazawa-ku, \\ Yokohama 236-0001, Japan
}

\begin{abstract}
Recruitment of Japanese sardine Sardinops melanostictus is related to interannual variability in the winter mixed layer depth (MLD) near the Kuroshio axis (line of maximum current), possible because MLD may influence the feeding environment of sardine larvae through phytoplankton productivity. However, a relationship between the winter MLD and phytoplankton productivity has not been shown. Particle release experiments with quasi-observed current fields from ocean reanalysis products and satellite-observed phytoplankton (chlorophyll a) density from 1998 to 2006 showed that deeper waters of the winter mixed layer flowing $0^{\circ}$ to $0.5^{\circ}$ north of the Kuroshio axis led to a greater bloom in the subsequent spring, although such a relationship was not detected south of the Kuroshio axis. By using the output of a 3-dimensional, high-resolution lower trophic level ecosystem model that reproduced the MLD-phytoplankton relationship, we found that entrainment of deeper nutrient-rich subsurface water leads to abundant nutrients in the early spring and enhances the subsequent spring bloom along the northern side of the Kuroshio axis. On the southern side, where mode water develops in winter, the deeper winter mixed layer does not necessarily contain higher nutrient contents, because nutrient vertical profiles often have inversions. These results support the hypothesis that sardine larvae that are distributed in the deeper winter mixed layer north of the Kuroshio axis (called the Kuroshio frontal zone) encounter a higher phytoplankton density, which yields favorable feeding conditions, resulting in recruitment success.
\end{abstract}

KEY WORDS: Mixed layer depth $\cdot$ Bloom $\cdot$ Kuroshio $\cdot$ Ecosystem model $\cdot$ Japanese sardine Resale or republication not permitted without written consent of the publisher

\section{INTRODUCTION}

Japanese sardine Sardinops melanostictus are known to undergo drastic and multi-decadal stock fluctuations (e.g. Ito 1961, Yasuda et al. 1999). The largest landing of sardine in Japan was 4.49 million tons in 1988 ; in contrast, the catch in recent years has been $<1 \%$ of this amount. Watanabe et al. (1995) attributed this drastic fluctuation in stock to large recruitment variability, especially with regards to the survival rate from the end of first-feeding larvae to age-1.

Recruitment variability has been attributed to differences in the physical environment and associated ecosystem in the Kuroshio system, where sardines spawn and their larvae are distributed. Noto \& Yasuda $(1999,2003)$ reported a relationship between sardine mortality and winter/spring sea-surface 
temperature (SST) in the Kuroshio Extension (KE) and its southern recirculation area $\left(\mathrm{KESA}_{;} 30^{\circ}\right.$ to $35^{\circ} \mathrm{N}, 145^{\circ}$ to $180^{\circ} \mathrm{E}$ ). Takasuka et al. (2007) reported an optimal temperature of $16.2^{\circ} \mathrm{C}$ for the growth rates of sardine larvae, suggesting the importance of environmental temperature. Nishikawa \& Yasuda (2008) reported significant negative correlations between mortality and the winter mixed layer depth (MLD) in regions of the KE and suggested the importance of spring feeding conditions, which may be controlled by the wintertime entrainment of subsurface nutrients. Takahashi et al. (2008, 2009) reported that interannual variations in the growth rates of early stage juveniles corresponded to recruitment variability in the low-stock period of 1996 to 2003.

More recently, Nishikawa et al. (2011) pointed out that sardine recruitment variability is related to the winter MLD and winter/spring SST near the Kuroshio axis ('axis' being defined as the positions representing the maximum current speed at each degree longitude), where sardine eggs were mainly spawned in the high-stock period of 1980 to 1994. Winter SST and MLD variability near the Kuroshio axis are caused by variability in the velocity of the Kuroshio jet and local atmospheric cooling, and are well correlated with SST in the KESA (Nishikawa \& Yasuda 2011). By performing numerical analyses of egg release based on spawning data from observations, Nishikawa et al. (2013) confirmed the dense distribution of sardine larvae near the Kuroshio axis and suggested that the environmental factors and transport routes critical to recruitment variability are the winter MLD and winter/spring SST from $0.5^{\circ}$ south to $1^{\circ}$ north of the Kuroshio axis, in both the high- and low-stock periods from 1978 to 2004 . The winter MLD-recruitment relationship near the Kuroshio axis (Nishikawa \& Yasuda 2008, Nishikawa et al. 2011, 2013) needs further study because no evidence exists to show that the relationship between the winter MLD and phytoplankton density influences the feeding environment of sardine larvae. Nishikawa \& Yasuda (2008) have, however, hypothesized, based on a simplified ecosystem model, that the spring bloom may be enhanced by entrainment of deeper subsurface water.

Nutrient, phytoplankton and zooplankton distributions and hydro- graphy are considerably different north and south of the Kuroshio axis (Kawai 1972, Nakata et al. 1995, 2004, Sukigara et al. 2011). For example, satellite data show a high density of chlorophyll a (chl a) along the northern side of the Kuroshio axis (Fig. 1), indicating its potential importance for sardine recruitment. On the northern side (or coastal side south of Japan) of the Kuroshio axis, the pycnocline and nutricline are shallow, at a depth of about $100 \mathrm{~m}$, and wintertime convective mixing entrains abundant subsurface nutrients. In contrast, on the southern (offshore) side of the Kuroshio axis, the pycnocline and nutricline are much deeper, down to $400 \mathrm{~m}$ depth, and the vertically uniform North Pacific Subtropical Mode Water (e.g. Masuzawa 1969) is distributed here. Along the southern edge of the Kuroshio axis, a narrow band of the warmest and least dense water in the area exists (referred to as the maximum temperature band; Kawai 1972). Thus, since the hydrographic structure is more complicated on the southern side of the Kuroshio axis than on the northern side, nutrient vertical profiles may also be more complicated. With respect to the processes of nutrient supply along the Kuroshio, Chu \& Kuo (2010) examined the pumping and advection of nutrients due to eddies associated with propagating Rossby waves in the KE. Yamazaki et al. (2009) suggested that enhanced vertical mixing along the Kuroshio over the Izu Ridge is a possible source of summertime nutrients in the KE.

Temporal variability in the winter/spring MLD and phytoplankton density around the Kuroshio, which we are also interested in, has previously been re-

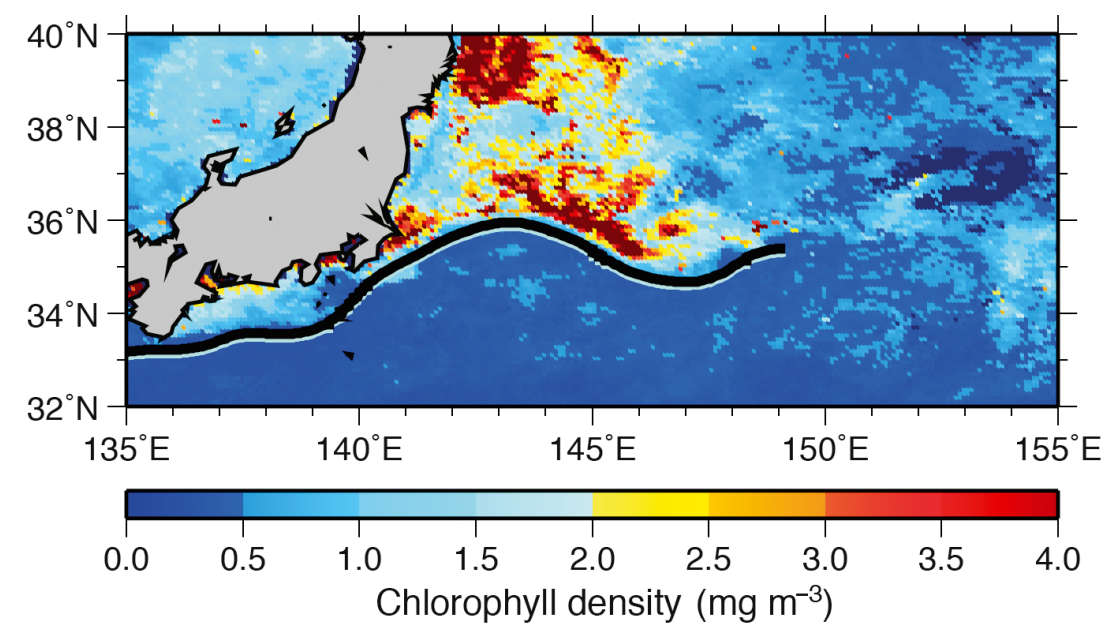

Fig. 1. Chlorophyll a density off the coast of Japan in April 2004 (SeaWiFS data). The black curve represents the Kuroshio axis (Marine Information Research Center 2007), based on observed sea-surface temperature (SST), sea-surface height ( $\mathrm{SSH}$ ) and surface velocity 
ported for the interannual variability of the MLD in the KESA (Yasuda et al. 2000) and for the relation between the winter MLD and spring chl $a$ on the southern side of the Kuroshio axis south of Japan (Limsakul et al. 2001) and in the KESA (Nishikawa \& Yasuda 2008). A MLD and chl a time-series in the KESA has been recorded using a float that drifted in the surface mixed layer for $1.5 \mathrm{yr}$ (Yasuda \& Watanabe 2007). However, these studies were not sufficient to resolve the cross-frontal structure of the Kuroshio.

In the present study, we examined the relationship between the winter MLD and phytoplankton density by using hydrographic reanalysis data and satellite observations of chl $a$, and compared the winter MLD and chl a density in winter and spring along the transport routes of sardine eggs and larvae from the Kuroshio south of Japan in winter to the KE area. We then also performed similar MLD-phytoplankton analyses with an ecosystem model, confirming that the model captured the observed relationship between MLD and phytoplankton density. We then tried to establish the specific processes and underlying mechanisms behind the relationship by using the model's output data.

\section{MATERIALS AND METHODS}

\section{MLD and chl a observations}

We used chl a data gathered by a SeaWiFS (seaviewing wide field-of-view sensor, NASA) satellite between 1998 and 2006 (the period when satellitederived chl a data were available), to examine the relationship between winter MLD and winter/spring phytoplankton density. The data used were standard mapped image products (Level-3), with $9 \mathrm{~km}$ horizontal and monthly resolutions. For quasi-observational environmental data of the MLD and ocean currents, FRA-JCOPE (Miyazawa et al. 2008) velocity and temperature data were used. FRA-JCOPE is an ocean general circulation model (OGCM) based on JCOPE (Japan Coastal Ocean Predictability Experiment, operated by the Frontier Research Center for Global Change of JAMSTEC), which is operated by the Fisheries Research Agency (FRA). FRA-JCOPE assimilates satellite sea-surface height (SSH), SST and hydrographic data from the Global TemperatureSalinity Profile Program (GTSPP) and has $1 / 12^{\circ} \times$ $1 / 12^{\circ}$ horizontal and daily resolutions. The FRAJCOPE model output best represents conditions near Japan. We define MLD as the depth at which temperature is $0.5^{\circ} \mathrm{C}$ lower than at the surface.

\section{Eddy-resolving coupled physical-biological model}

To determine the underlying processes behind the MLD-phytoplankton relationship, we used the output of an eddy-resolving coupled physical-biological model (Sasai et al. 2006, 2010) for the period from 2001 to 2007 . The physical model is the ocean general circulation model for the earth simulator (OFES) (Masumoto et al. 2004, Sasaki et al. 2008), which is based on the Geophysical Fluid Dynamics Laboratory's modular ocean model (MOM3) (Pacanowski \& Griffies 2000). The horizontal resolution is $0.1^{\circ}$. There are 54 vertical levels with varying distances between the levels, from $5 \mathrm{~m}$ at the surface to $330 \mathrm{~m}$ at the maximum depth of $6065 \mathrm{~m}$. After the physical fields have been spun up for $50 \mathrm{yr}$ under monthly mean climatological data from NCEP/ NCAR (National Centers for Atmospheric Prediction/National Center for Atmospheric Research), OFES is forced by the daily mean NCEP/NCAR reanalysis data (Kalnay et al. 1996) for 48 yr from 1950 to 1998 . The last day of 1998 is used for the initial physical fields in this simulation.

The marine ecosystem model is a simple nitrogenbased NPZD (nitrogen, phytoplankton, zooplankton and detritus) pelagic model (Oschlies 2001). The evolution of any biological tracer concentration is governed by an advection-diffusion equation with source and sink terms. The source and sink terms represent the ecosystem dynamics (Sasai et al. 2006, 2010). The phytoplankton growth rate depends on the light intensity, nitrate concentration and temperature (Eppley 1972). The light intensity is given by the NCEP/NCAR shortwave radiation. The initial nitrate field is taken from the climatological dataset (WOA98). The coupled physical-biological model is forced by the daily mean surface wind stress data of Quick Scatterometer (QSCAT) and the atmospheric daily mean data (heat and salinity fluxes) of the NCEP/NCAR reanalysis data (1999 to 2007): these are initialized from a $5 \mathrm{yr}$ spin up of the biological model under the monthly mean climatological forcing of NCEP, following a $98 \mathrm{yr}$ integration of the physical model.

We used $3 \mathrm{~d}$ snapshot output of the coupled physical-biological model. The $3 \mathrm{~d}$ interval data were interpolated into 20 min intervals for particle tracking. The simulated phytoplankton density $\left(\mathrm{mmol} \mathrm{m}^{-3}\right)$ was converted to chl a density using a ratio of $1.59 \mathrm{~g}$ chl a mol${ }^{-1}$ nitrogen (e.g. Oschlies 2001).

In this physical-biological model, the Kuroshio path variability was not necessarily realistic, because no oceanic observational data were assimi- 
lated. Since the MLD and its variability near the Kuroshio axis are strongly influenced by velocity and local atmospheric forcing (Nishikawa \& Yasuda 2011), model reproduction of year-to-year MLD variability near the Kuroshio axis is not complete due to the unrealistic Kuroshio path variability in this model. This might cause the winter MLD difference between the model and observations. However, we believe that it is worthwhile to further explore the relationship between the winter MLD and spring phytoplankton in the model, because the model enables us to examine specific processes connecting winter MLD and spring phytoplankton by providing time-series data on nutrients, whereas observational field data are quite limited.

Another issue is that the phytoplankton in this model tends to be overestimated in comparison to the observed values near the Kuroshio axis. Since hydrography, nutrients and, thus, phytoplankton change considerably across the Kuroshio axis and are influenced by various complicated processes, such as horizontal and vertical advections and mixing as well as nitrate fixation, nitrification and atmospheric deposition, accurate determinations of nutrients and phytoplankton are quite difficult to achieve. Furthermore, since this global coupled physical-biological model considers each bio-geochemical parameter as spatially uniform rather than spatially variable depending on the location in the Kuroshio region (Sasai et al. 2006, 2010), it is difficult to accurately reproduce all of the variables in this complicated region.

\section{Particle tracking experiment}

We released particles to simulate sardine eggs and larvae on the FRA-JCOPE and coupled physicalbiological model velocity fields. Particles were released in sardine spawning grounds in the Kuroshio, south of Japan, in the areas from $130^{\circ}$ to $140^{\circ} \mathrm{E}$ and from the coast to $1.5^{\circ}$ south of the Kuroshio axis, at $0.2^{\circ}$ latitude and longitude intervals. Since the spawning of the Japanese sardine Sardinops melanostictus is greatest in February (Nishikawa et al. 2013), particles were released on 15 February in each year from 1998 to 2006 for the FRA-JCOPE and from 2001 to 2007 for the coupled physical-biological model. For the FRA-JCOPE, MLD and chl a were recorded along particle trajectories from Days 0 to 75. For the coupled physical-biological model, nitrate concentrations were also recorded to better understand phytoplankton variation.
Particles were released at the shallow depth of $2.5 \mathrm{~m}$, because particle distribution is not sensitive to release depth (Nishikawa et al. 2013) in a range from the surface to $50 \mathrm{~m}$, where sardine eggs and larvae are mainly observed (Konishi 1980). Since correlations between sardine recruitment and transport environment were found for larvae that were distributed near the Kuroshio axis and transported to the $\mathrm{KE}$ east of $142^{\circ} \mathrm{E}$ (Nishikawa et al. 2013), we selected particles that were distributed within the area from $1.5^{\circ}$ south to $1.5^{\circ}$ north of the Kuroshio axis and reaching east of $142^{\circ} \mathrm{E}$ by Day 75 . These particles were divided into 2 groups (GR1 and GR2, to the north and south of the Kuroshio axis, respectively; Fig. 2) and further subdivided into 6 subgroups at $0.5^{\circ}$ intervals (GR1a to GR1c and GR2a to GR2c; Table 1). Correlation analyses were performed among mean environmental parameters (MLD and nitrate) and $\mathrm{chl}$ a/phytoplankton density for each transport route.

Fig. 3 shows an example of particle tracking in the FRA-JCOPE case for particles along the GR1c route (Table 1) that were released on 15 February 2005 and were transported along the route $0^{\circ}$ to $0.5^{\circ}$ north of the Kuroshio axis and to the KE east of $142^{\circ} \mathrm{E}$. We show 3 snapshots of particle locations on 15 February, 15 March and 15 April. Almost all the particles appeared in the $\mathrm{KE}$ east of $142^{\circ} \mathrm{E}$ by 15 April.

\section{Phytoplankton and nitrate balance analysis in the ecosystem model}

The temporal variation in phytoplankton density and source-sink terms in the surface mixed layer were evaluated by following particle drift in the surface current. The time change rate of vertically uni-

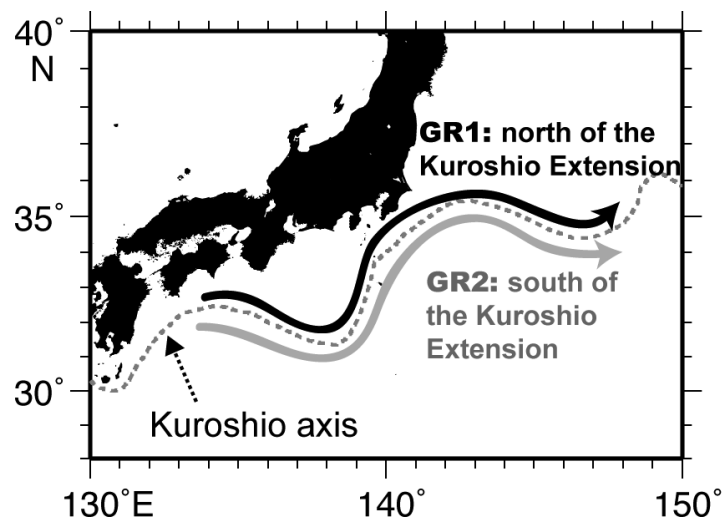

Fig. 2. Representative sardine transport routes: GR1 and GR2. Each route is further subdivided across the Kuroshio axis in $0.5^{\circ}$ intervals of latitudinal distance relative to the Kuroshio axis 
Table 1. Pearson correlations among winter (15 February to 31 March) mixed layer depth (wMLD), spring (1 to 30 April) chl a density (sCHL) or phytoplankton density (sPHY), winter nitrate concentration (wNTR) and winter chl a density (wCHL) or phytoplankton density (wPHY) for 9 yr of observed data (1998 to 2006) and for 7 yr of model data (2001 to 2007) along 6 transport routes (GR1a to GR1c and GR2a to GR2c) from $1.5^{\circ}$ north to $1.5^{\circ}$ south of the Kuroshio axis (at $0.5^{\circ}$ intervals). GR1 and GR2 are north and south of the Kuroshio axis, respectively. p-values given in parentheses. See Figs. $4 \& 5$ for details on observed and modeled data, respectively, for routes GR1c and GR2a. ${ }^{*} 0.05<\mathrm{p}<0.1,{ }^{* *} \mathrm{p} \leq 0.05$

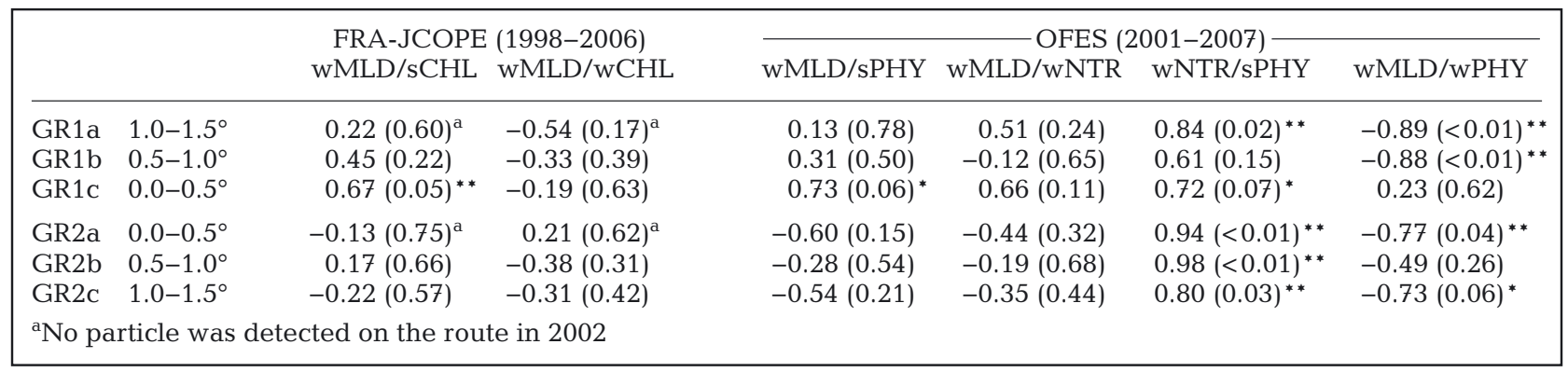

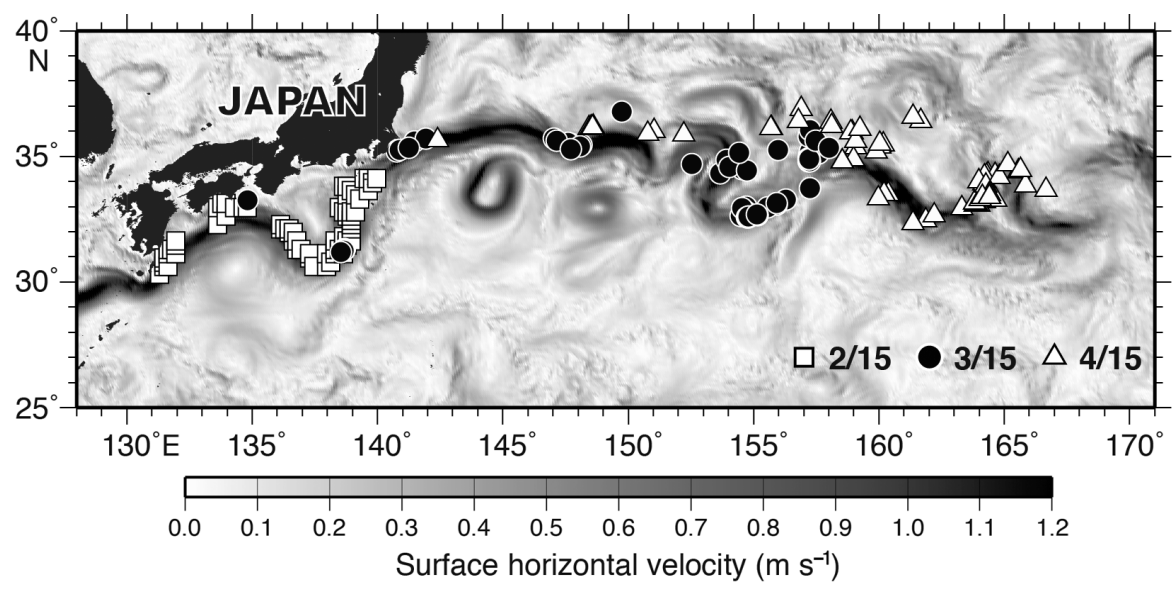

Fig. 3. Location of particles that were released on 15 February 2005 and transported along the route $0^{\circ}$ to $0.5^{\circ}$ north of the Kuroshio axis and to the Kuroshio Extension east of $142^{\circ} \mathrm{E}$ (corresponding to GR1c in Table 1) superimposed on FRA-JCOPE velocity field data for 15 April (shading). ( $\square$ ) Locations on 15 February (denoting starting spawning grounds along the GR1c route); (†) 15 March; and $(\Delta)$ on 15 April

form phytoplankton in the surface mixed layer was approximated as:

$$
\frac{\mathrm{d} P}{\mathrm{~d} t}=\begin{aligned}
& \text { photosynthesis-grazing- } \\
& \text { natural mortality-entrainment }
\end{aligned}
$$

where $P$ is the phytoplankton averaged in the mixed layer and $\mathrm{d} / \mathrm{d} t$ is the Lagrangian time derivative following the particle surface velocity. The natural mortality term consists of the specific mortality (or recycling) rate (from phytoplankton to nitrate) and the quadratic mortality rate (from phytoplankton to detritus) (Sasai et al. 2006, 2010). Underestimation of primary production in the standard NPZD model is resolved by adding a rapid recycling path from simulated phytoplankton back to the nitrate compartment. To restrict the overestimation of primary pro- duction in oligotrophic regions, phytoplankton loss to the detritus compartment was changed from a linear function of phytoplankton concentration to a quadratic function (Oschlies 2001).

The temporal change of MLDintegrated nitrate per unit area is determined by the 4 following factors in the model. First is the entrainment of subsurface water with a generally higher nitrate concentration. This depends on vertical mixing and mixed layer deepening and is here referred to as ' $\mathrm{EN}^{\prime}$ '. Although entrainment decreases phytoplankton density (fourth term of right hand side in Eq. 1), due to the dilution of entrained water with less phytoplankton, entrainment increases nitrate concentration. Second is the decomposition of organic matter: detritus, zooplankton and phytoplankton. This is independent of the MLD and is referred to as ' $\mathrm{DN}$ '. The third factor in the model is the consumption of nitrate due to uptake during photosynthesis. The fourth factor is the loss of nitrate in the period of mixed layer shoaling, although nitrate concentration in the mixed layer is unchanged.

\section{RESULTS}

\section{Relationship between MLD and chl a/phytoplank- ton near the Kuroshio axis}

Results of the correlation analysis for winter (defined in the present study as 15 February to 31 March) 
MLD, spring (1 to 30 April) chl a/phytoplankton density, winter nitrate concentration and winter phytoplankton density, along the 6 larval transport routes, are summarized in Table 1.

Significant positive correlation $(\mathrm{r}=0.67, \mathrm{p}=0.05$, $\mathrm{n}=9$ ) was only detected for the route $0^{\circ}$ to $0.5^{\circ}$ north of the Kuroshio axis (GR1c) between mean winter MLD and mean spring chl a (Table 1). Correlation for the transport route $0.5^{\circ}$ to $1.0^{\circ}$ north of the Kuroshio axis (GR1b) $(\mathrm{r}=0.45, \mathrm{p}=0.22, \mathrm{n}=9)$ was positive. A scatter plot between winter MLD and spring chl $a$ is depicted in Fig. 4 a for the GR1c route. For the MLD of 80 to $120 \mathrm{~m}$, chl a ranged from $\sim 0.45$ to $0.65 \mathrm{mg} \mathrm{m}^{-3}$.

For the routes south of the Kuroshio axis, no significant correlations were detected between observed winter MLD and spring chl a. A scatter plot between observed winter MLD and spring chl a for the GR2a route $\left(0^{\circ}\right.$ to $0.5^{\circ}$ south of the Kuroshio axis) is depicted in Fig. 4C; MLD and chl a ranged from 120 to $140 \mathrm{~m}$ and 0.35 to $0.56 \mathrm{mg} \mathrm{m}^{-3}$, respectively.

For the observed winter MLD and winter chl $a$, correlations were mostly negative, except along the GR2a route (Table 1, Fig. 4d); in years with a deeper winter mixed layer, winter chl a tended to be lower. The scatter plots for GR1c (Fig. 4b) indicate that winter chl a ranged from 0.24 to $0.31 \mathrm{mg} \mathrm{m}^{-3}$ for the winter MLD of 80 to 120 m. For GR2a (Fig. 4d), winter chl a ranged from 0.23 to $0.32 \mathrm{mg} \mathrm{m}^{-3}$ for the winter MLD of 120 to $140 \mathrm{~m}$.

In the model, a positive correlation between winter MLD and spring phytoplankton density was detected along routes GR1b ( $\mathrm{r}=0.31, \mathrm{p}=0.5, \mathrm{n}=7)$ and GR1c $(\mathrm{r}=0.73, \mathrm{p}=0.06, \mathrm{n}=7$ ) (Table 1). For GR1c, both observations and the model indicated that spring $\mathrm{chl}$ a/phytoplankton tends to be higher in years of large winter MLD. The scatter plot for the GR1c model (Fig. 5a) indicated that, for an MLD of 60 to $110 \mathrm{~m}$, phytoplankton ranged from 0.55 to $0.85 \mathrm{mg} \mathrm{m}^{-3}$. The phytoplankton in the model was greater than that observed (Fig. 4a). In the model route GR1c, positive correlations were detected between winter MLD and winter nitrate concentration $(\mathrm{r}=0.66, \mathrm{p}=0.1, \mathrm{n}=7$; Fig. $5 \mathrm{~b})$ and between winter nitrate concentration and spring phytoplankton $(\mathrm{r}=0.72, \mathrm{p}=0.07$, $\mathrm{n}=7$; Fig. 5c).

Along the routes south of the Kuroshio axis (GR2), correlations were negative between model winter MLD and spring phytoplankton (Table 1, Fig. 5e), in contrast with the GR1c route. This is because while the spring phytoplankton depends on the winter nitrate (Fig. 5g), the deep mixed layer does not necessarily entrain more nitrate in winter (Fig. 5f). For the model relationship between winter MLD and winter phytoplankton, negative correlations were mostly significant, except for GR1C, because of light limitation due to a deeper mixed layer in winter.

Although the year of large winter MLD and high spring chl a/phytoplankton did not completely agree for the GR1c between observations and the model, positive correlations were detected between winter MLD and spring chl a/phytoplankton in both the observations $(\mathrm{r}=0.67$; Table 1$)$ and the model $(\mathrm{r}=$ 0.73 ). The top 4 years in terms of MLD (i.e. the years with the largest MLD) were 2004, 2001, 2000 and 2005 in the observations, while the top years in the model were 2005, 2003, 2004 and 2002 (Figs. 4a \& 5a). This discrepancy in MLDs between the observations and model may also have caused the spring chl a/phytoplankton density difference; the 4 years of greatest spring chl a/phytoplankton density were 2004, 2005, 2000 and 2002 in the observations,

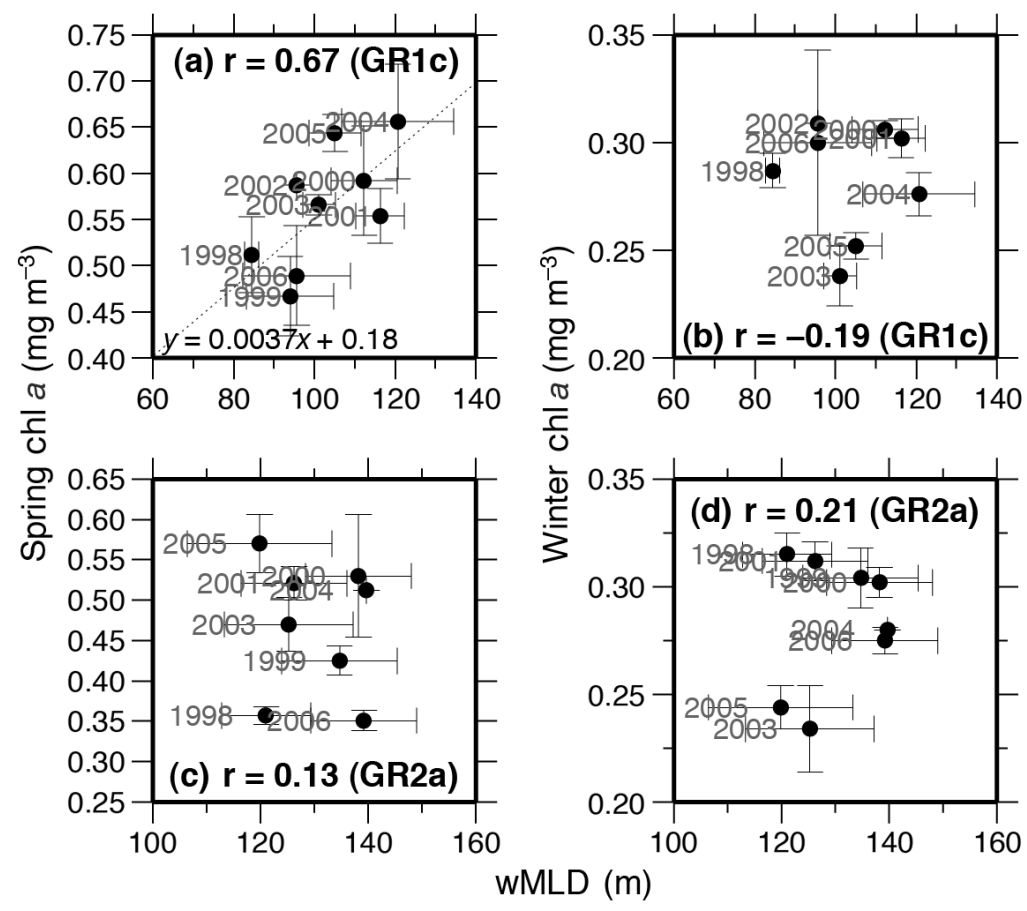

Fig. 4. Observed data (1998 to 2006) on (a) winter mixed layer depth (wMLD; $\mathrm{m}$ ) versus spring chl a density $\left(\mathrm{mg} \mathrm{m}^{-3}\right)$, with the regression line shown, and (b) wMLD versus winter chl a density, both for the GR1c route $\left(0^{\circ}\right.$ to $0.5^{\circ}$ north of the Kuroshio axis); and (c) wMLD versus spring chl a density and (d) wMLD versus winter chl a density, both for the GR2a route $\left(0^{\circ}\right.$ to $0.5^{\circ}$ south of the Kuroshio axis). Numerals denote years; error bars: $95 \%$ confidence intervals $(1.96 \times$ standard error $)$ 


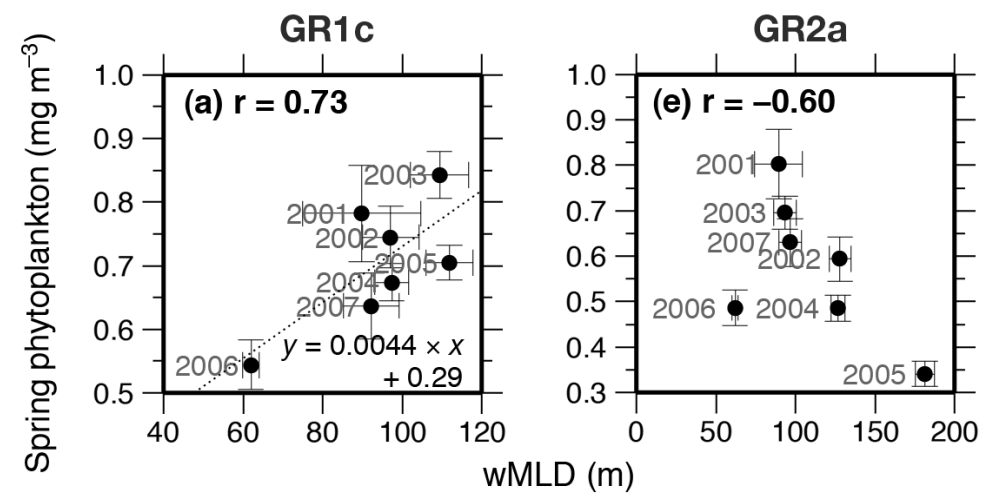

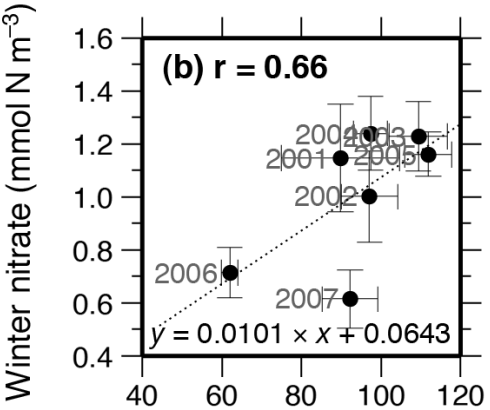

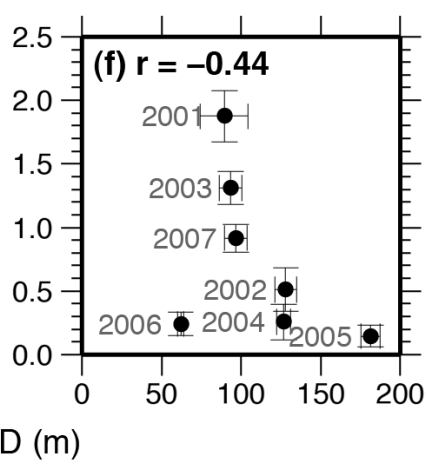

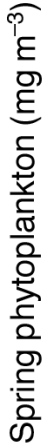
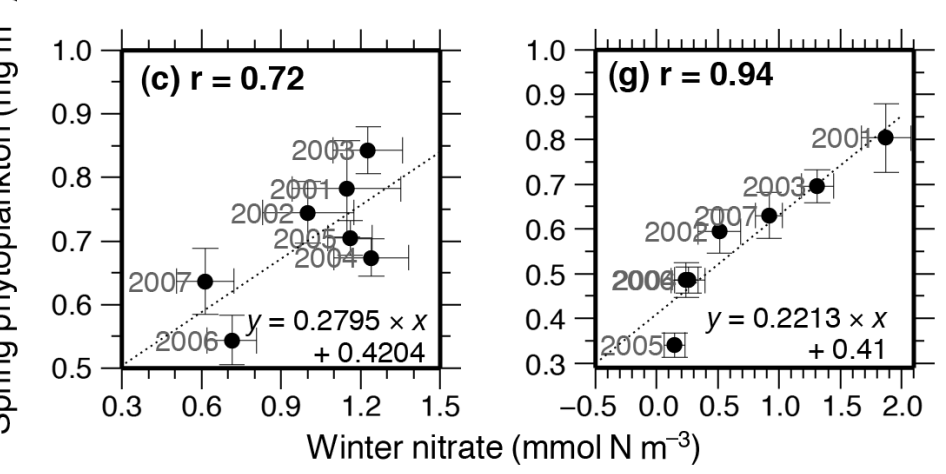

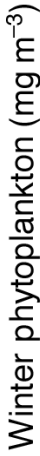

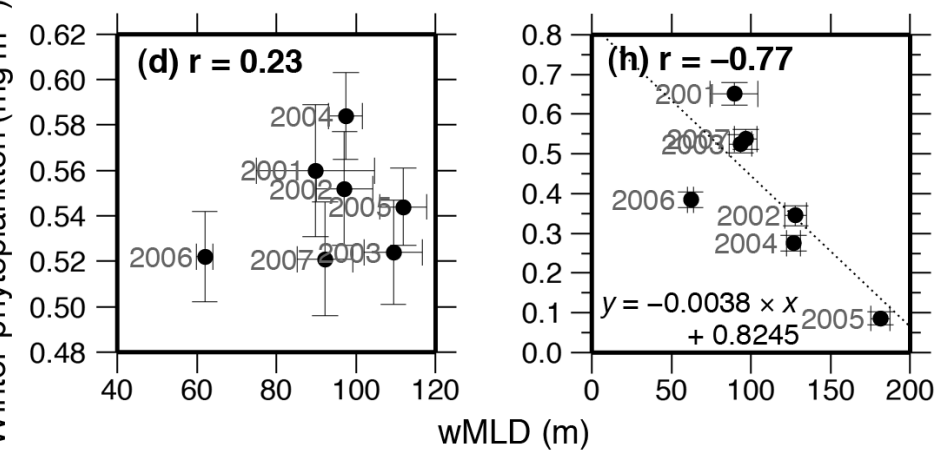

Fig. 5. Modeled data (2001 to 2007) for $(\mathrm{a}-\mathrm{d})$ the GR1c route $\left(0^{\circ}\right.$ to $0.5^{\circ}$ north of the Kuroshio axis) and (e-h) the GR2a route $\left(0\right.$ to $0.5^{\circ}$ south of the Kuroshio axis). (a,e) Winter mixed layer depth (wMLD; m) and spring phytoplankton $\left(\mathrm{mg} \mathrm{m}^{-3}\right),(\mathrm{b}, \mathrm{f}) \mathrm{wMLD}$ and winter nitrate concentration (mmol $\left.\mathrm{N} \mathrm{m}^{-3}\right)$, (c,g) winter nitrate and spring phytoplankton, and $(\mathrm{d}, \mathrm{h})$ wMLD and winter phytoplankton. Regression lines are displayed in Panels a-c, g and $h$, with correlations of $>90 \%$ confidence whereas they were 2003, 2001, 2002 and 2005 in the model.

\section{Processes north of the Kuroshio axis}

Here we examined time-series of physical and biological properties to better understand the processes behind the relationships among the MLD, nitrate and phytoplankton along the GR1c route, with a positive correlation between winter MLD and spring chl a/phytoplankton (Figs. 4a \& 5a). We examined the 2 contrasting years of 2005 and 2006. The year 2005 represented a large winter MLD and a high spring phytoplankton density, and the year 2006 showed the opposite trend.

Winter MLDs averaged from 15 February to 31 March were $112.5 \mathrm{~m}$ in 2005 and $62.1 \mathrm{~m}$ in 2006 (Fig. 6a). Spring (from 1 to 30 April) MLDs were $76.2 \mathrm{~m}$ in 2005 and $85.2 \mathrm{~m}$ in 2006. Fig. 6b shows time-series of phytoplankton averaged for the mixed layer.

While spring-averaged phytoplankton in $2005\left(0.71 \mathrm{mg} \mathrm{m}^{-3}\right)$ was higher than that in 2006 (0.54 $\mathrm{mg} \mathrm{m}^{-3}$ ) (Fig. 6b), the phytoplankton values on 12 March in 2005 and 2006 were almost the same-0.46 $\mathrm{mg} \mathrm{m}^{-3}$ in 2005 and $0.48 \mathrm{mg} \mathrm{m}^{-3}$ in 2006. The increase of phytoplankton due to photosynthesis from 12 March to 30 April (time-integration of the first term on the right hand side of Eq. 1) was estimated at $8.02 \mathrm{mg} \mathrm{m}^{-3}$ in 2005 and $5.81 \mathrm{mg} \mathrm{m}^{-3}$ in 2006. The decrease in phytoplankton from 12 March to 30 April by grazing was $4.63 \mathrm{mg} \mathrm{m}^{-3}$ in 2005 and $3.35 \mathrm{mg} \mathrm{m}^{-3}$ in 2006, the decrease by natural mortality was 2.30 and $1.76 \mathrm{mg} \mathrm{m}^{-3}$, and the decrease by entrainment was 0.96 and $0.69 \mathrm{mg}$ $\mathrm{m}^{-3}$, respectively. Because all terms on the right hand side of Eq. 1 in Eq. (1) in 2005 were higher than those in 2006, photosynthesis was the only component that yielded a higher phytoplankton density in 2005.

Photosynthesis in the mixed layer depends on nitrate concentration and light intensity in the mixed layer. Because spring mean MLDs were almost the same in 2005 and 2006 (76.2 m in 2005 and $85.2 \mathrm{~m}$ in 2006), spring MLD was not a primary cause of the photosynthesis difference. Instead, the greater winter MLD in 2005 than in 2006 caused a higher nitrate level (Fig. 7a) and more active photosynthesis (Fig. 6b) in 2005. 

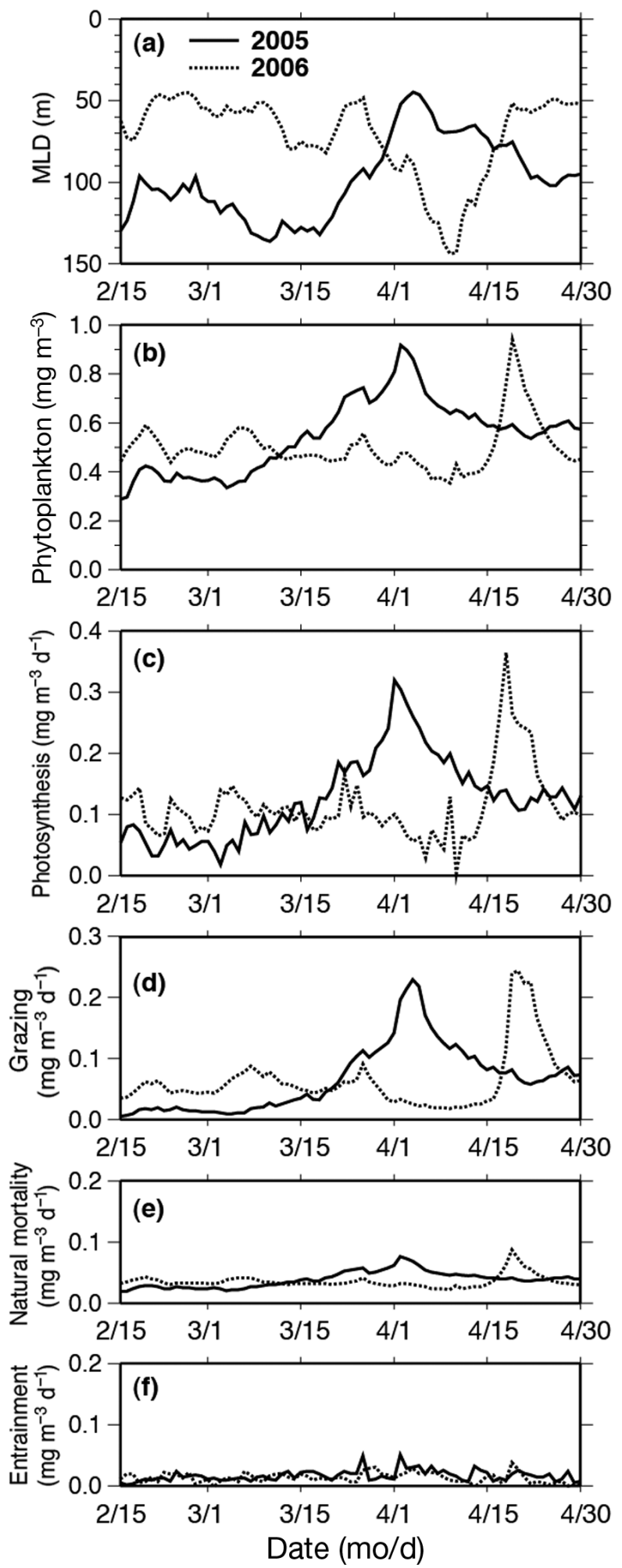

Fig. 6. (a) Mixed layer depth (MLD), (b) phytoplankton averaged in the mixed layer for the GR1c route, and (c-f) source or sink terms for phytoplankton in Eq. (1): (c) phytoplankton growth rate by photosynthesis, (d) grazing rate by zooplankton, (e) natural mortality rate and (f) dilution rate by vertical entrainment. Each rate is estimated on a chl $a$ basis $\left(\mathrm{mg} \mathrm{m}^{-3} \mathrm{~d}^{-1}\right)$
The next question was why the nitrate concentration was higher in 2005 than in 2006. The nitrate balance from winter to spring in both years is shown in Table 2. At the beginning of particle tracking on 15 February, there was little difference between the nitrate inventory (nitrate integrated in the mixed layer per unit area) in 2005 and in 2006 (Table 2a). During the winter (15 February to 31 March) of 2005 , the total supply of nitrate was twice as high as that during the winter of 2006 (Table 2b). This difference was mainly caused not by decomposition of organic matter (DN) but by the nitrate supplied by mixed layer deepening (EN). EN was several times larger than DN and was the main source of the nitrate supply (Fig. 7b,c). Since EN depended on the MLD, wintertime entrainment of nitrate in 2005 was greater than in 2006, corresponding to a greater winter MLD (112.5 m) in 2005 than in 2006 (62.1 m) (Fig. 6a).

Nitrate consumed during photosynthesis in winter (Table 2c) and nitrate loss by mixed layer shoaling in winter (Table 2d) were higher in 2005 than in 2006; however, the residual nitrate concentration was higher by $116.6 \mathrm{mmol} \mathrm{N} \mathrm{m}^{-2}$ in 2005, because of a more abundant nitrate supply during winter due to the deeper mixed layer in 2005. Differences in nitrate between 2005 and 2006, in the mixed layer on 15 February (Table 2a), and in the nitrate supplies by entrainment (Table 2b) and decomposition (Table 2c) during winter were 24.7, 190.2 and $31.7 \mathrm{mmol} \mathrm{N} \mathrm{m}^{-2}$, respectively. Thus, most of the difference in the residual nitrate at the end of the winter was explained by the nitrate supply due to entrainment, that is, due to the winter MLD.

There was little difference between nitrate supply in spring (1 to 30 April) in 2005 and in 2006 (Table 2f). Also, loss of nitrate by mixed layer shoaling in spring in both years was similar (Table $2 \mathrm{~h}$ ). The nitrate that can be used for spring photosynthesis was residual nitrate at the end of the winter + spring nitrate supply - loss of nitrate by mixed layer shoaling in spring: $321.6 \mathrm{mmol} \mathrm{N} \mathrm{m}^{-2}$ in 2005 and $199.8 \mathrm{mmol} \mathrm{N} \mathrm{m}^{-2}$ in 2006 (Table 2i). Because the difference between 2005 and 2006 in spring nitrate supply was relatively minor, the total difference $\left(121.8 \mathrm{mmol} \mathrm{N} \mathrm{m}^{-2}\right)$ between 2005 and 2006 was predominantly caused by the difference in residual nitrate at the end of the winter in each year (116.6 mmol $\mathrm{N} \mathrm{m}^{-2}$; Table $2 \mathrm{e}$ ).

Nitrate consumed by spring photosynthesis was $270.9 \mathrm{mmol} \mathrm{N} \mathrm{m}^{-2}$ in 2005 and $196.0 \mathrm{mmol} \mathrm{N} \mathrm{m}^{-2}$ in 2006 (Table 2g). Thus, the winter nitrate supply, especially the nitrate supply caused by the deepening of the winter mixed layer, determined the spring 

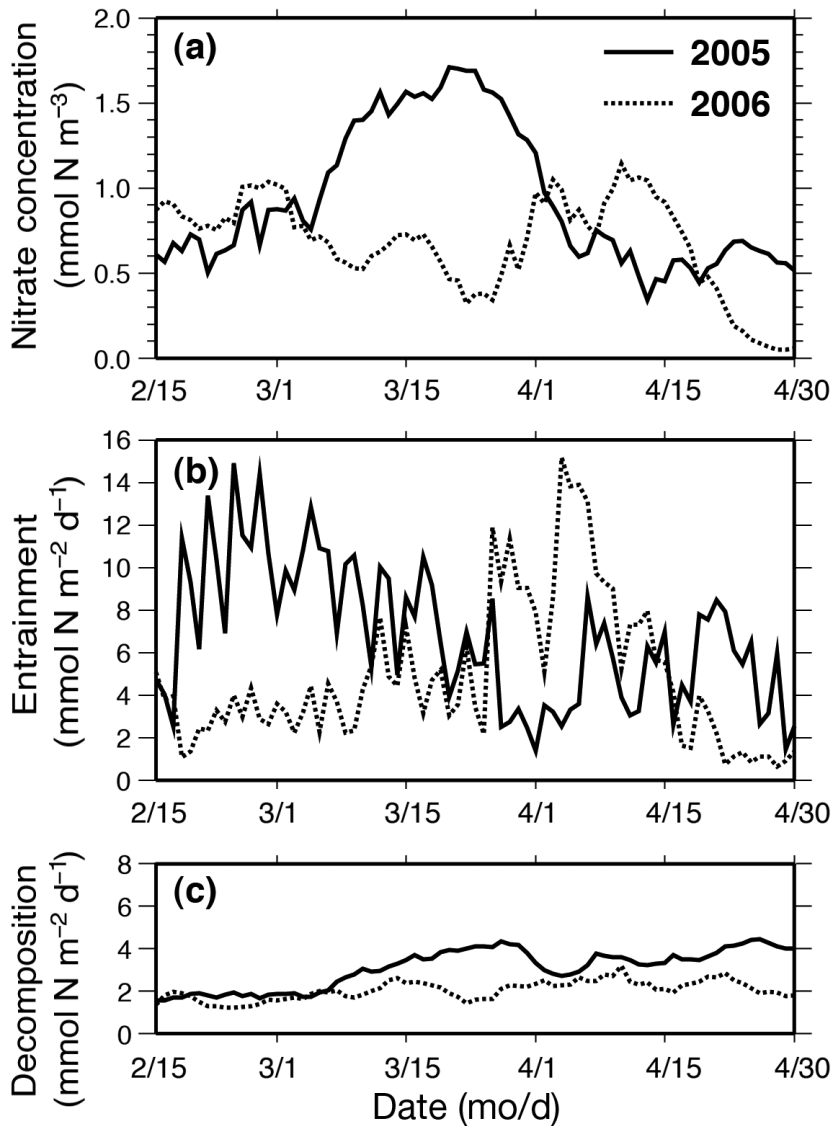

Fig. 7. (a) Nitrate concentration averaged in the surface mixed layer and the rate of nitrate supply (in mmol $\mathrm{N} \mathrm{m}^{-2} \mathrm{~d}^{-1}$ ) to the mixed layer for the GR1c route by (b) entrainment and (c) decomposition of organic matter in the ecosystem model

nitrate concentration and phytoplankton abundance in the model. A similar relationship between the winter nitrate supply through mixed layer deepening and spring photosynthesis was also seen for other years (Table $2 \mathrm{~b}, \mathrm{~g}$ ). The 3 years of the most winter entrainment were 2002, 2003 and 2005; these corresponded to the 3 years of greatest spring consumption during photosynthesis (Table $2 \mathrm{~b}, \mathrm{~g}$ ). These were also deep winter mixed layer years (Fig. 5a).

When we compared mean nitrate distributions in the model on the northern side of the Kuroshio axis between February and April (Fig. 8), the nitrate concentration in the mixed layer was much higher in February than in April; this is because phytoplankton consumes nitrate in the mixed layer in spring.

\section{Processes south of the Kuroshio axis}

In the GR2 routes, where particles are transported on the southern side of the Kuroshio axis, spring

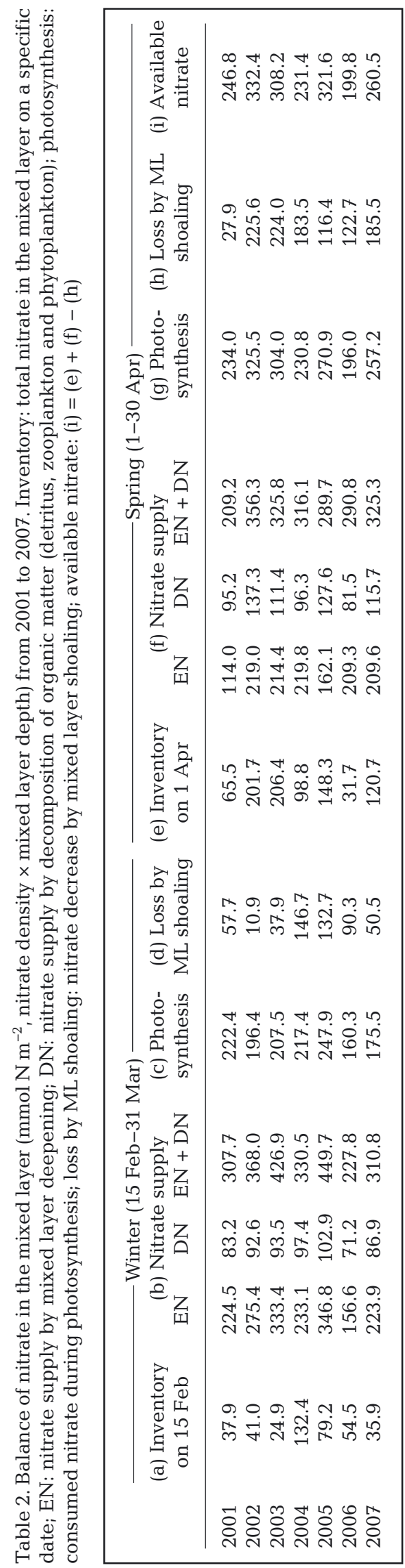



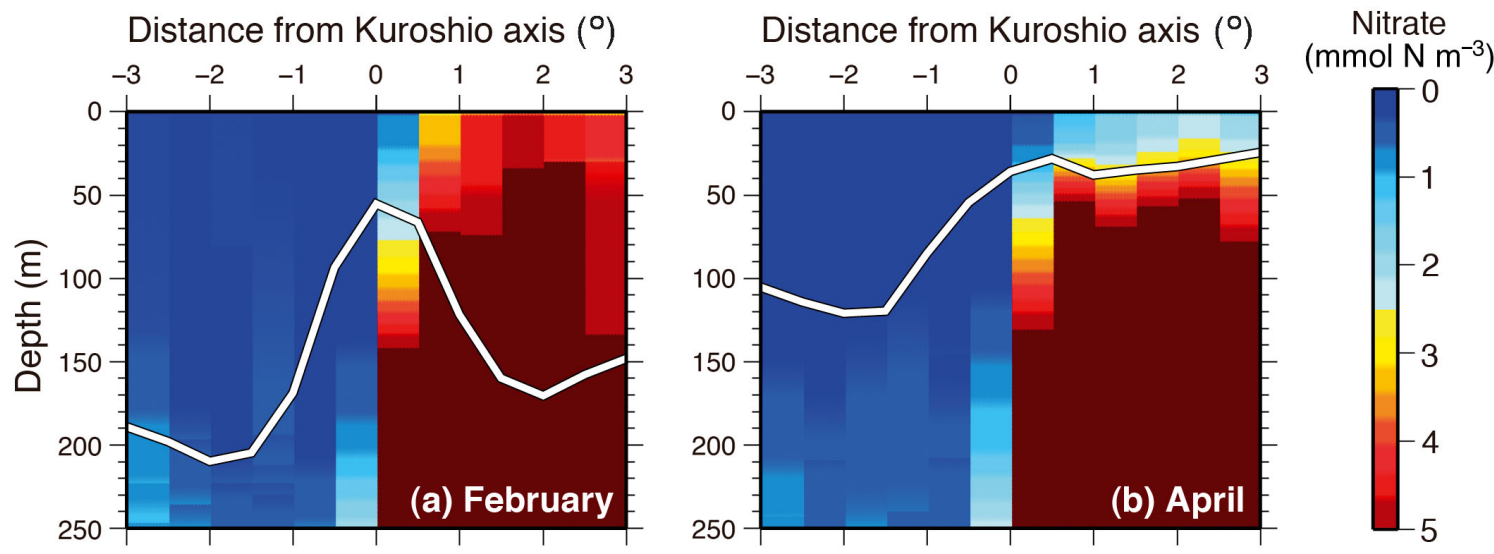

Fig. 8. Mean vertical sections of nitrate across the Kuroshio axis along $142^{\circ} \mathrm{E}$ in (a) February and (b) April, according to the ecosystem model. Average distance $\left({ }^{\circ}\right.$ ) from the Kuroshio axis is given for 2001 to 2007 ; the positive (negative) numbers denote north (south) of the axis. White line: mixed layer depth

phytoplankton densities were not necessarily high in years of a deep winter mixed layer (Table 1). On the other hand, significant positive correlations were detected between winter nitrate and spring chl a/ phytoplankton (Table 1). Along the GR2 routes, a deeper winter mixed layer did not always lead to a higher winter nitrate concentration.

Fig. 9 represents the time-series of MLD and nitrate concentration along the GR2a route $\left(0^{\circ}\right.$ to $0.5^{\circ}$ south of the Kuroshio axis) in 2005 and 2006. 2005 (2006) is the year when the winter mixed layer was deep (shallow). Although the winter mean MLD in $2005(181 \mathrm{~m})$ was much greater than in $2006(76 \mathrm{~m})$ (Fig. 9a), the winter mean nitrate concentration in $2005\left(0.25 \mathrm{mmol} \mathrm{N} \mathrm{m}^{-3}\right)$ was not as high as in 2006 $\left(0.44 \mathrm{mmol} \mathrm{N} \mathrm{m}^{-3}\right.$ ) (Fig. 9b); this was unlike the situation along route GR1c on the northern side of the Kuroshio axis (Fig. 7a).

The independence of nitrate concentration from MLD is shown in the area where nitrate-poor water was distributed below the surface mixed layer. Fig. 10a depicts the modeled vertical cross-section of nitrate in February 2005. A vertical inversion of nitrate concentration was seen at the depth of 130 to $170 \mathrm{~m}$ at $31.4^{\circ} \mathrm{N}$ on the southern side of the Kuroshio axis. During such an inversion, mixed layer deepening is expected to entrain nitrate-poor water and to reduce the nitrate concentration in the surface mixed layer.

Such vertical inversions of nitrate concentration (represented by the occurrence rate of a nitrate minimum layer just below the surface mixed layer, based on the eddy-resolving coupled physical-biological model) frequently occur on the southern side of the Kuroshio axis, whereas they rarely occur on the northern side (Fig. 11). While the rate was $<10 \%$ in the waters 0 to $3^{\circ}$ north of the Kuroshio axis (GR1), the rate was 15 to $20 \%$ on the southern side (GR2). Thus, a deeper winter mixed layer did not always lead to higher nitrate concentrations in the surface mixed layer along the GR2 in the model.

Nitrate vertical inversions were actually observed on the southern side of the Kuroshio axis. A nitrate inversion was seen at around $100 \mathrm{~m}$ depth from $29.5^{\circ}$ to $32.5^{\circ} \mathrm{N}$ (Fig. 10b). As for the modeled data, obser-
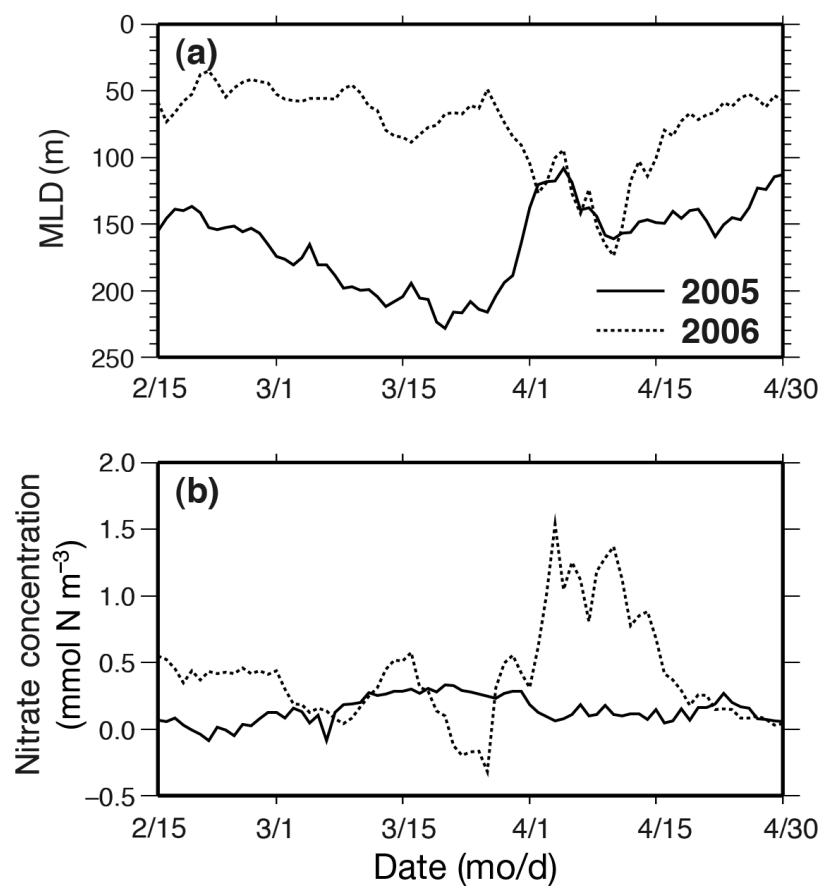

Fig. 9. (a) Mixed layer depth (MLD; m) and (b) nitrate concentration averaged in the surface mixed layer, and the rate of nitrate supply (in mmol $\mathrm{N} \mathrm{m}^{-2} \mathrm{~d}^{-1}$ ) to the mixed layer for the GR2a route $\left(0^{\circ}\right.$ to $0.5^{\circ}$ south of the Kuroshio axis) 

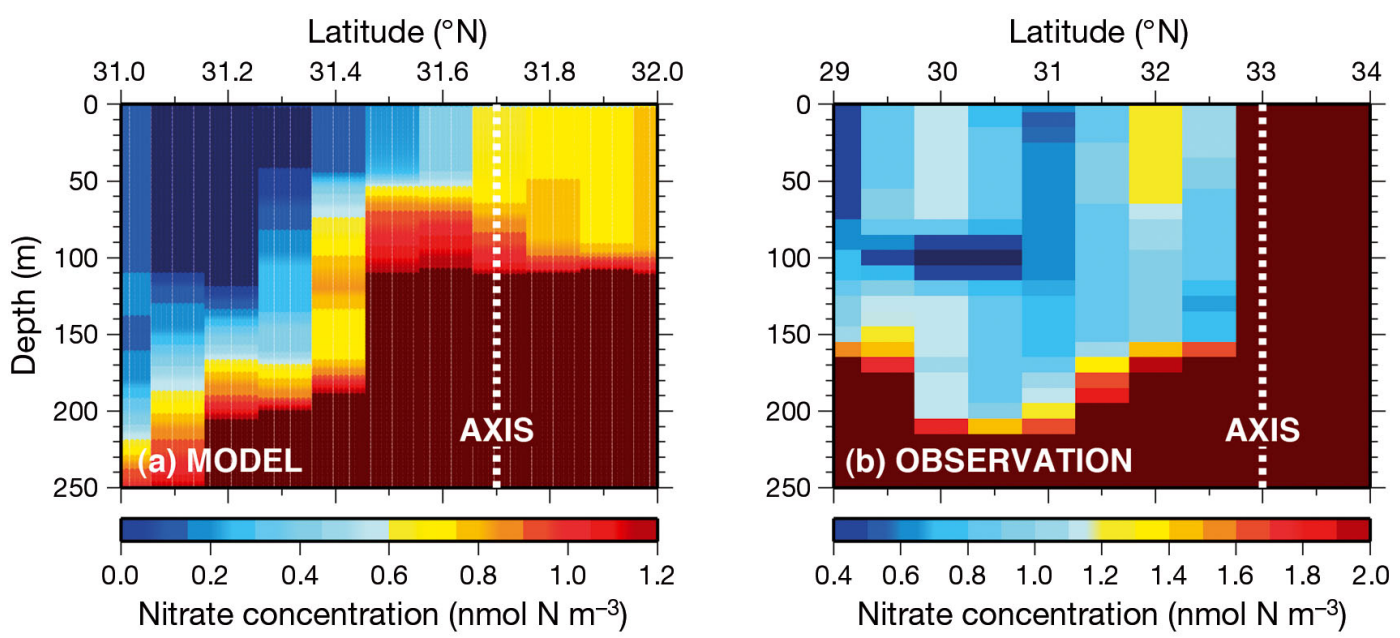

Fig. 10. Vertical cross-sections of nitrate according to the (a) ecosystem model from $31^{\circ}$ to $32^{\circ} \mathrm{N}$ along $133^{\circ} \mathrm{E}$ on 20 February 2005 and for (b) observations from $29^{\circ}$ to $34^{\circ} \mathrm{N}$ along $137^{\circ} \mathrm{E}$ in winter 2010 during the Ryofu Maru cruise (Japan Meteorological Agency 2010). Broken lines denote the Kuroshio axis. Since the grid interval is different between the model $\left(0.1^{\circ}\right)$ and observations $\left(0.5^{\circ}\right)$, the latitudinal ranges differ between (a) and (b)

vational data analysis did not detect correlations between spring phytoplankton and winter MLD along the GR2 either (Table 1).

\section{DISCUSSION}

Positive correlations were detected between winter MLD and spring phytoplankton density in the water mass that is transported by the Kuroshio along the route $0^{\circ}$ to $0.5^{\circ}$ north of the Kuroshio axis in both the observations from 1998 to 2006 and the ecosystem model for 2001 to 2007, where the deeper winter mixed layer entrains higher nitrate concentrations, resulting in enhancement of the spring phytoplankton bloom. The route $0^{\circ}$ to $0.5^{\circ}$ north of the Kuroshio axis and to the KE was a main transport route of sardine larvae, and there were significant positive correlations between MLD and sardine recruitment during the period from 1978 to 1994 (Nishikawa et al. 2013). Especially, the regime shift of the mixed layer from deep to shallow in 1988 might have caused the sudden decrease of sardine stock (Yasuda et al. 2000, Nishikawa \& Yasuda 2008, 2011, Nishikawa et al. 2011, 2013). Combination of the these previous studies and our results, and the positive correlation between MLD and phytoplankton density give an important implication for sardine stock variation. Since copepod eggs and nauplii are the main food source of sardine larvae (Nakata et al. 1995), low spring chl a, corresponding to a shallow winter mixed layer, might worsen the feeding conditions for sardine larvae; this is because the relationship between chl $a$ and nauplius density is not linear (Dr. Tohru Ikeya pers. comm. in 2010), and egg production stops at a chl a density lower than a certain threshold value; in the case of Calanus sinicus, for example, eggs are produced when the chl a density is $>0.5 \mathrm{mg} \mathrm{m}^{-3}$ (Uye \& Murase 1997). Along the route $0^{\circ}$ to $0.5^{\circ}$ north of the Kuroshio axis, the mean (from 1998 to 2006) observed spring chl a density was $0.56 \mathrm{mg} \mathrm{m}^{-3}$. But the density was $<0.5 \mathrm{mg} \mathrm{m}^{-3}$ in shallow mixed layer years, 1999 and 2006 (Fig. 4a), when sardine recruitment was also low (Fisheries Agency and Fisheries Research Agency of Japan 2007). The shallow winter mixed layer $(<100 \mathrm{~m}) 0^{\circ}$ to $0.5^{\circ}$ north of the Kuroshio axis may thus have caused unfavorable feeding conditions for sardine larvae and decreased recruitment from 1988 to 1990. Nishikawa

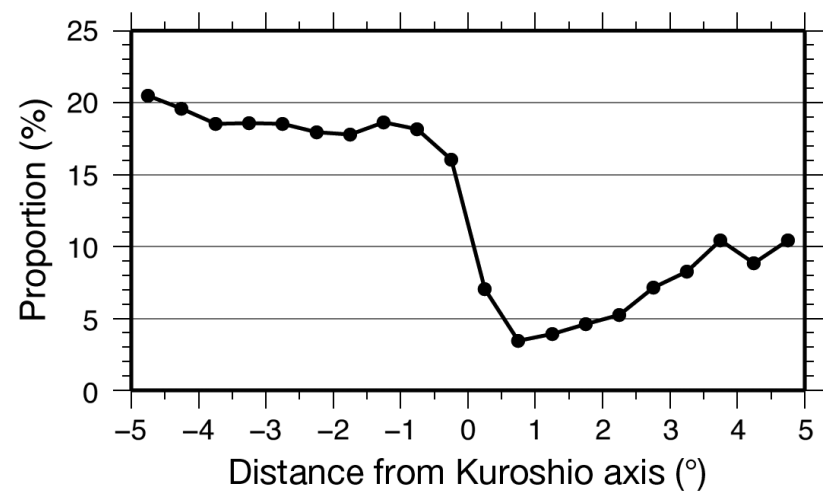

Fig. 11. Frequency (in percent) of the model grids with the nitrate minimum layer just below the surface mixed layer from $130^{\circ}$ to $160^{\circ} \mathrm{E}$ around the Kuroshio axis in March. The positive (negative) numbers denote north (south) of the Kuroshio axis 


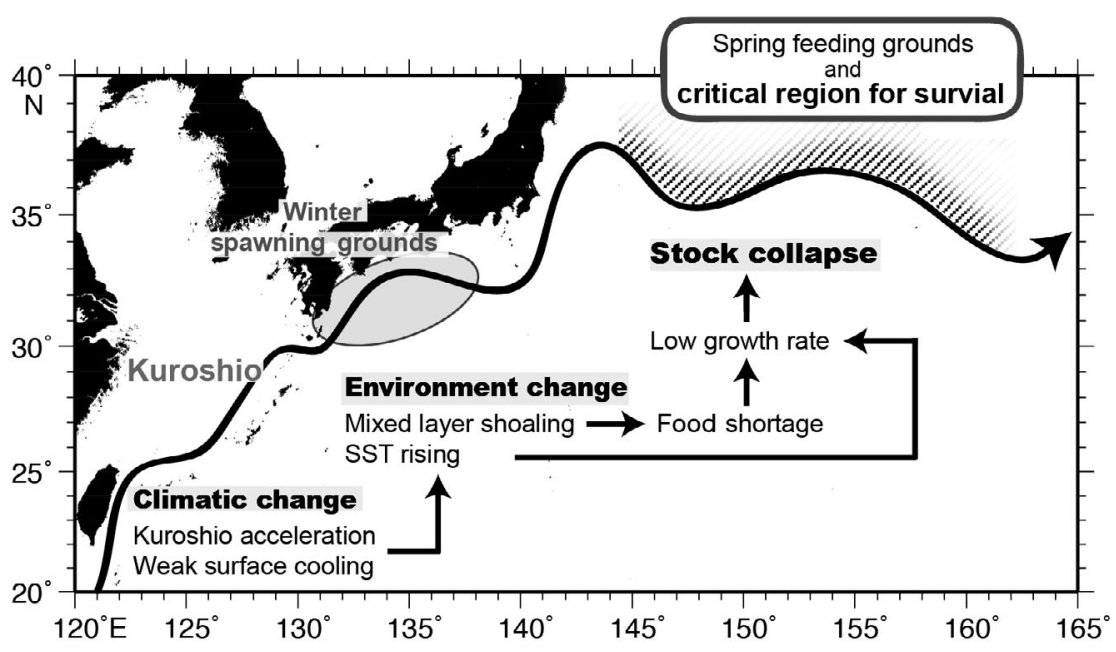

Fig. 12. Hypothesis of how climate change may have led to the collapse of the sardine Sardinops melanostictus stock off Japan

et al. (2011) showed that the mean February MLD $0^{\circ}$ to $0.5^{\circ}$ north of the Kuroshio axis and from $130^{\circ}$ to $160^{\circ} \mathrm{E}$ from 1988 to 1990 was $77 \mathrm{~m}$, whereas it was $109 \mathrm{~m}$ from 1980 to 1987 according to OFES data.

In observations, positive correlations were also seen between winter MLD and spring chl a of the water mass along the transport route $0.5^{\circ}$ to $1^{\circ}$ north of the Kuroshio axis. Since MLDs that larvae experience along this route are positively correlated with sardine recruitment (Nishikawa et al. 2011, 2013), MLD variation on this route might also affect the survival of sardine larvae through feeding conditions. These 2 areas $0^{\circ}$ to $1^{\circ}$ north of the Kuroshio axis with positive correlations between winter MLD and spring chl $a$ are the main larval transport routes. More than $15 \%$ of total larvae are distributed here (Nishikawa et al. 2013). These large proportions of the larval distribution suggest the importance of the winter MLD along these 2 routes for sardine recruitment.

Considering our findings that winter MLD variations do not necessarily lead to spring phytoplankton variability, winter MLD variations south of the Kuroshio axis may not be a dominant factor contributing to recruitment variability, although Nishikawa et al. (2011, 2013) reported significant positive correlations just south of the Kuroshio axis, where a significant amount of larvae are transported.

The shallow mixed layer near the Kuroshio axis at the end of the 1980s was caused primarily by acceleration of the Kuroshio jet and the reduction of surface cooling (Nishikawa \& Yasuda 2011). The strong current velocity reduces the time during which the mixed layer is exposed to wintertime cooling. As a result, the winter mixed layer does not deepen. These climate changes also cause a high SST (Nishikawa \&
Yasuda 2011). High SST in 1988 cooccurring with a shallow mixed layer could have a negative influence on larvae and recruitment. Larval growth rate is highest at $16.2^{\circ} \mathrm{C}$ (Takasuka et al. 2007). However, the SST that larvae experienced along the GR1c route from 1988 to 1992 was 17 to $18^{\circ} \mathrm{C}, 0.5^{\circ} \mathrm{C}$ higher than in the early 1980s (Nishikawa et al. 2012).

The synergetic effects of feeding and environmental temperature changes could affect larval survival. Fig. 12 illustrates our hypothesis that climatic variability induces sardine stock collapse. Sardine spawning grounds are formed from the coasts south of Japan to the Kuroshio axis. Eggs and larvae are transported by the Kuroshio near the Kuroshio axis, and, as observed, large portions are transported to the Kuroshio Extension (Sugisaki 1996, Kinoshita 1998). Here we hypothesize that important factors affecting sardine recruitment variability through feeding conditions may be limited by winter MLD variability $0^{\circ}$ to $1^{\circ}$ north of the Kuroshio axis, the area usually regarded as Kuroshio frontal zone. The winter MLD variability is caused by variability of local wind cooling and the Kuroshio jet velocity.

Acknowledgements. The present paper is part of a $\mathrm{PhD}$ thesis by H.N. at the Graduate School of Science, University of Tokyo. The authors thank Profs. E. Oka, Y. Watanabe, H. Nakamura and M. Uematsu for their useful comments. This study was partially supported by KAKENHI\#20221002 and SUPRFISH.

\section{LITERATURE CITED}

Chu PC, Kuo YH (2010) Nutrient pumping/advection by propagating Rossby waves in the Kuroshio extension. Deep-Sea Res II 57:1809-1819

Eppley RW (1972) Temperature and phytoplankton growth in the sea. Fish Bull 70:1063-1085

Fisheries Agency and Fisheries Research Agency of Japan (2007) Marine fisheries stock assessment and evaluation for Japanese waters (details for fiscal year 2007). Fisheries Agency and Fisheries Research Agency of Japan, Tokyo, p 11-44 (in Japanese). Also available at: http:// abchan.job.affrc.go.jp/digests19/details/1901.pdf

Ito S (1961) Fisheries biology of the sardine, Sardinops melanostictus (T. \& S.), in the waters around Japan. Bull Jpn Sea Natl Fish Res Inst 9:1-227 (in Japanese with English abstract)

Japan Meteorological Agency (2010) Oceanographic and marine meteorological observations by research vessels, Ryofu Maru 1001 cruise. Available at: www.data.kishou. go.jp/kaiyou/db/vessel_obs/data-report/html/ship/cruise 
data_e.php?id=RF1001 (accessed on 30 July 2010)

Kalnay E, Kanamitsu M, Kistler R, Collins W and others (1996) The NCEP/NCAR 40-year reanalysis project. Bull Am Meteorol Soc 77:437-471

Kawai H (1972) Hydrography of the Kuroshio Extension. In: Stommel H, Yoshida K (eds) Kuroshio, its physical aspects. University of Tokyo Press, Tokyo, p 235-352

Kinoshita T (1998) Northward migrating juveniles in the Kuroshio Extension area. In: Watanabe Y, Wada T (eds) Stock fluctuations and ecological changes of the Japanese sardine. Koseisha-Koseikaku, Tokyo, p 84-92 (in Japanese)

Konishi Y (1980) Vertical distribution of eggs and larvae of sardine, Sardinops melanosticta (T. et S.), and round herring, Etrumeus micropus (T. et S.). Bull Nansei Reg Fish Res Inst 12:93-103

Limsakul A, Saino T, Midorikawa T, Goes JI (2001) Temporal variations in lower trophic level biological environments in the northwestern North Pacific subtropical gyre from 1950 to 1997. Prog Oceanogr 49:129-149

Marine Information Research Center, Japan Hydrographic Association (2007) Data sets of the axis of the Kuroshio from 1955 to 2006. CD-ROM. Japan Hydrographic Association, Tokyo

Masumoto Y, Sasaki H, Kagimoto T, Komori N and others (2004) A fifty-year eddy-resolving simulation of the world ocean-preliminary outcomes of OFES (OGCM for the Earth Simulator). J Earth Sim 1:35-56

Masuzawa J (1969) Subtropical mode water. Deep-Sea Res 16:463-472

Miyazawa Y, Komatsu K, Setou T (2008) Nowcast skill of the JCOPE2 ocean forecast system in the Kuroshio-Oyashio mixed water region. J Mar Meteorol Soc (Umi to Sora) 84:85-91 (in Japanese with English abstract)

Nakata K, Zenitani H, Inagake D (1995) Differences in food availability for Japanese sardine larvae between the frontal region and the waters on the offshore side of Kuroshio. Fish Oceanogr 4:68-79

Nakata K, Itoh H, Ichikawa T, Sasaki K (2004) Seasonal changes in the reproduction of three oncaeid copepods in the surface layer of the Kuroshio Extension. Fish Oceanogr 13:21-33

- Nishikawa H, Yasuda I (2008) Japanese sardine (Sardinops melanostictus) mortality in relation to the winter mixed layer depth in the Kuroshio Extension region. Fish Oceanogr 17:411-420

Nishikawa H, Yasuda I (2011) Long-term variability of winter mixed layer depth and temperature along the Kuroshio jet in a high-resolution ocean general circulation model. J Oceanogr 67:503-518

Nishikawa H, Yasuda I, Itoh S (2011) Impact of winter-tospring environmental variability along the Kuroshio jet on the recruitment of Japanese sardine (Sardinops melanostictus). Fish Oceanogr 20:570-582

Nishikawa H, Yasuda I, Itoh S, Komatsu K, Sasaki H, Sasai Y, Oozeki Y (2013) Transport and survival of Japanese sardine (Sardinops melanostictus) eggs and larvae via particle tracking experiments. Fish Oceanogr (in press)

Noto M, Yasuda I (1999) Population decline of the Japanese sardine, Sardinops melanostictus, in relation to sea surface temperature in the Kuroshio Extension. Can J Fish Aquat Sci 56:973-983

Noto M, Yasuda I (2003) Empirical biomass model for the Japanese sardine, Sardinops melanostictus, with sea surface temperature in the Kuroshio Extension. Fish
Oceanogr 12:1-9

> Oschlies A (2001) Model-derived estimates of new production: New results point towards lower values. Deep-Sea Res II 48:2173-2197

Pacanowski RC, Griffies SM (2000) MOM 3.0 manual. Geophysical Fluid Dynamics Laboratory/National Oceanic and Atmospheric Administration, Princeton, NJ

Sasai Y, Ishida A, Sasaki H, Kawahara S, Uehara H, Yamanaka Y (2006) A global eddy-resolving coupled physical-biological model: physical influences on a marine ecosystem in the North Pacific. Simul-T Soc Mod Sim 82: 467-474

Sasai Y, Richards KJ, Ishida A, Sasaki H (2010) Effects of cyclonic mesoscale eddies on the marine ecosystem in the Kuroshio extension region using an eddy-resolving coupled physical-biological model. Ocean Dyn 60:693-704

Sasaki H, Nonaka M, Masumoto Y, Sasai Y, Uehara H, Sakuma H (2008) An eddy-resolving hindcast simulation of the quasiglobal ocean from 1950 to 2003 on the Earth Simulator. In: Ohfuchi W, Hamilton K (eds) High resolution numerical modelling of the atmosphere and ocean. Springer, New York, NY, p 157-186

Sugisaki H (1996) Distribution of larval and juvenile Japanese sardine (Sardinops melanostictus) in the western North Pacific and its relevance to predation on these stages. In: Watanabe Y, Yamashita Y, Oozeki Y (eds) Survival strategies in early life stages of marine resources. A.A. Balkema, Rotterdam, p 261-270

Sukigara C, Suga T, Saino T, Toyama K, Yanagimoto D, Hanawa K, Shikama N (2011) Biogeochemical evidence of large diapycnal diffusivity associated with the subtropical mode water of the North Pacific. J Oceanogr 67:77-85

> Takahashi M, Nishida H, Yatsu A, Watanabe Y (2008) Yearclass strength and growth rates after metamorphosis of Japanese sardine (Sardinops melanostictus) in the western North Pacific ocean during 1996-2003. Can J Fish Aquat Sci 65:1425-1434

> Takahashi M, Watanabe Y, Yatsu A, Nishida H (2009) Contrasting responses in larval and juvenile growth to a climate-ocean regime shift between anchovy and sardine. Can J Fish Aquat Sci 66:972-982

> Takasuka A, Oozeki Y, Aoki I (2007) Optimal growth temperature hypothesis: Why do anchovy flourish and sardine collapse or vice versa under the same ocean regime? Can J Fish Aquat Sci 64:768-776

Uye S, Murase A (1997) Relationship of egg production rates of the planktonic copepod Calanus sinicus to phytoplankton availability in the Inland Sea of Japan. Plankton Biol Ecol 44:3-11

- Watanabe Y, Zenitani H, Kimura R (1995) Population decline of the Japanese sardine Sardinops melanostictus owing to recruitment failures. Can J Fish Aquat Sci 52:1609-1616

> Yamazaki H, Iwamatsu I, Hasegawa D, Nagai T (2009) Chlorophyll patches observed during summer in the main stream of the Kuroshio. Atmos-ocean 47:299-307

> Yasuda I, Watanabe T (2007) Chlorophyll a variation in the Kuroshio extension revealed with a mixed-layer tracking float: implication on the long-term change of Pacific saury (Cololabis saira). Fish Oceanogr 16:482-488

- Yasuda I, Sugisaki H, Watanabe Y, Minobe SS, Oozeki Y (1999) Interdecadal variations in Japanese sardine and ocean/climate. Fish Oceanogr 8:18-24

Yasuda I, Tozuka T, Noto M, Kouketsu S (2000) Heat balance and regime shifts of the mixed layer in the Kuroshio extension. Prog Oceanogr 47:257-278 